\title{
Divergence of male courtship displays between sympatric forms of anadromous threespine stickleback
}

\author{
Jun Kitano ${ }^{1)}$, Seiichi Mori ${ }^{2)}$ \& Catherine L. Peichel ${ }^{1,3)}$ \\ $\left({ }^{1}\right.$ Division of Human Biology, Fred Hutchinson Cancer Research Center, Seattle, WA \\ 98109, USA; ${ }^{2}$ Biological Laboratory, Gifu-keizai University, Ogaki, Gifu 503-8550, Japan)
}

(Accepted: 30 December 2007)

\begin{abstract}
Summary
Courtship displays are an important component of animal reproduction, and divergence in these displays can play an integral role in promoting or maintaining reproductive isolation between species. The courtship behaviour of the threespine stickleback (Gasterosteus aculeatus) has been extensively characterized. In Japan, there are two lineages of threespine stickleback that are genetically differentiated and reproductively isolated when found in regions of sympatry. We have previously shown that males of the Pacific Ocean lineage perform the zig-zag dance, while sympatric males of the Japan Sea lineage perform a different dance, which we have termed the rolling dance (Kitano et al., 2007, Biol. J. Linn. Soc. 91: 671-685). As a first step towards understanding the role of the courtship display in female mate choice and sexual isolation between this sympatric pair, we conducted a more detailed analysis of divergence between the courtship displays of the Pacific Ocean and Japan Sea males. Kinematic analysis revealed that the tempo of the zig-zag dance is two times faster than the tempo of the rolling dance. A detailed analysis of head movements during the courtship dance revealed that the Japan Sea males erect their gill covers, extend their red throats, and open their mouths more frequently during the rolling dance than the Pacific Ocean males do during the zig-zag dance. These results demonstrate that there is extensive divergence between sympatric Pacific Ocean and Japan Sea males in both the motor patterns and the tempo of their courtship displays. Thus, the Japanese sympatric stickleback pair provides a good system to study the role of courtship behaviour in speciation, as well as the genetic mechanisms that underlie the divergence of kinematics and motor patterns in courtship behaviour.
\end{abstract}

Keywords: Gasterosteus aculeatus, zig-zag dance, courtship behaviour, motor pattern, kinematics, gill cover erection, high-speed video, tempo, nest.

\footnotetext{
3) Corresponding author's e-mail address: cpeichel@fhcrc.org
} 


\section{Introduction}

Movement is an important component of animal communication in a variety of organisms (Tinbergen, 1951; Lorenz, 1958; von Frisch, 1967; Brown et al., 2005). Movement can directly transmit information, such as the location of food resources in honeybee (von Frisch, 1967) or asymmetry of body shape in human (Brown et al., 2005). In addition, movement can enhance the detection or the stimulatory effects of other aspects of a signal, such as color, shape, sound, and posture (Hailman, 1977; Fleishman, 1992; Partan \& Marler, 1999; Künzler \& Bakker, 2001; Cooper \& Goller, 2004; Rosenthal et al., 2004). For example, vocalization in túngara frogs is usually accompanied by the inflation of a conspicuous vocal sac, which enhances the attractiveness of males (Rosenthal et al., 2004). The kinematic variables of a movement will determine the efficiency of its use in animal communication. For example, movements should be performed at an optimum velocity in order to effectively elicit the receiver's response (Fleishman, 1992; Rowland, 1995) and should be designed to enhance the signal over moving background noise (Fleishman, 1992; Peters \& Evans, 2003). Thus, kinematic studies of movements are necessary to understand the functions of these displays in animal communication. Furthermore, divergence in courtship displays can play an important role in sexual isolation between closely related species (Mayr, 1942; Tinbergen, 1951); thus, studies on divergence in the kinematics of courtship displays can contribute to an understanding of the speciation process.

The courtship rituals of the male threespine stickleback (Gasterosteus aculeatus) have been extensively studied in the context of animal communication, behavioural ecology, behavioural evolution, and speciation (Tinbergen, 1951; Wootton, 1984; McLennan et al., 1988; Bell \& Foster, 1994; Foster, 1995, 1999; Foster et al., 1996; McKinnon \& Rundle, 2002). In a majority of threespine stickleback populations, the appearance of a gravid female induces a territorial male to perform a stereotyped courtship dance known as a zig-zag dance (Tinbergen, 1951, 1953; Wootton, 1984). The male zig-zag dance plays an important role in attracting female attention, as well as in female mate choice and sexual isolation (Tinbergen, 1951; McPhail \& Hay, 1983; Jamieson \& Colgan, 1989; Rowland, 1995; Künzler \& Bakker, 2001; but see Milinski \& Bakker, 1990; Boughman et al., 2005). Despite the fact that one kinematic variable (the tempo of the male courtship dance) has been 
shown to influence female responses in the threespine stickleback (Rowland, 1995), there have been very few studies of variation in the kinematics of the male courtship dance across threespine stickleback populations.

In Japan, there are two genetically, morphologically and behaviourally distinct lineages of anadromous threespine stickleback, the Japan Sea and Pacific Ocean lineages (Haglund et al., 1992; Higuchi \& Goto, 1996; Ishikawa \& Mori, 2000; Ishikawa et al., 2006; Kitano et al., 2007). Although the distributions of these two lineages are overlapping in eastern Hokkaido, Japan, they are reproductively isolated even in regions of sympatry (Higuchi \& Goto, 1996; Kitano et al., 2007). Our previous mate choice experiment revealed asymmetric sexual isolation between the sympatric Pacific Ocean anadromous (PA) and Japan Sea anadromous (JA) forms: the PA females strongly prefer the PA males, while the JA females show no preference for JA males over PA males (Kitano et al., 2007). In order to understand which male mating signals contribute to sexual isolation between the Japanese sympatric pair, it is necessary to make a detailed comparison of the male mating signals in this sympatric pair. We have previously shown that these two sympatric forms have divergent courtship behaviours. Pacific Ocean males perform the zig-zag dance, while Japan Sea males do not perform the zig-zag dance and instead perform a behaviour that we have called the rolling dance (Kitano et al., 2007), which has previously been called the lateral display (Ishikawa \& Mori, 2000; Ishikawa et al., 2006). In addition to using this sympatric pair to study the potential role of courtship behaviour in sexual isolation, the striking differences in courtship behaviour provide an opportunity to study the genetic basis for the evolution of courtship behaviour, using the recently established genomic tools in stickleback (Peichel et al., 2001; Kingsley \& Peichel, 2007). To this end, we conducted a more detailed analysis of divergence in the kinematics and display behaviours of male courtship dances between Pacific Ocean and Japan Sea males.

\section{Material and methods}

Stickleback samples

Anadromous threespine sticklebacks of the sympatric Pacific Ocean (PA) and Japan Sea (JA) forms were collected from Akkeshi Bay (Kume et al., 2005), Japan, in May 2003, 2005 and 2006. First, the PA and JA forms 
were distinguished by external morphology: PA fish are larger than JA fish in standard length, and the caudal lateral plates are larger and more robust in PA fish than in JA fish (Ikeda, 1933; Higuchi \& Goto, 1996). In addition, after behavioural experiments, all fish were genotyped with lineage-diagnostic microsatellite markers to confirm the initial classification of fish into the PA and JA populations (Kitano et al., 2007). Fish collected in 2003 were used for kinematic analysis. For analysis of mouth opening and throat extension, we used fish collected in 2005. For analysis of gill cover erection, we used fish collected in 2005 and 2006.

\section{Kinematic analysis of the male courtship dance}

For analysis of kinematic variables during the male courtship dance, we analyzed movies that were recorded with a digital camcorder from the dorsal side of the fish at 30 frames per second (fps) (Kitano et al., 2007). Briefly, each plastic tank ( $40 \mathrm{~cm}$ wide $\times 75 \mathrm{~cm}$ long $\times 20 \mathrm{~cm}$ deep) was divided into a larger male compartment $(40 \mathrm{~cm}$ wide $\times 60 \mathrm{~cm}$ long $\times 20 \mathrm{~cm}$ deep $)$ and a smaller female compartment ( $40 \mathrm{~cm}$ wide $\times 15 \mathrm{~cm}$ long $\times 20 \mathrm{~cm}$ deep) by a fixed transparent partition. A male threespine stickleback with red nuptial coloration was placed in the male compartment and provided with nesting materials, consisting of boiled palm fibers $(10 \mathrm{~g})$ and a nesting tray filled with sand. Once the male built a nest, a gravid female of the same form was placed in the female compartment to stimulate the nesting male to perform a courtship dance. Curtains were arranged so that the testing tank was isolated from other tanks and the experimenter.

We analyzed the kinematics of a single approach toward a female for 10 different PA and 10 different JA males. Both types of approaches usually consist of repeated bouts of a behaviour (for the zig-zag dance, see van Iersel, 1953; Sevenster, 1961): the male usually starts from a steady upright posture, approaches the female, returns to a steady upright posture, then repeats this pattern several times. We defined a single motif as a behavioural component that starts from an upright position with a straight body shape and ends at the next upright position with a straight body shape (Figure 1). An approach composed of at least one C-turn and at least one undulation with an S-form was defined as a single motif of the zig-zag approach (Kitano et al., 2007; see also Figure 1A). An approach that lacks the S-undulation and instead contains rolling was defined as a single motif of the rolling approach (Kitano 
et al., 2007; see also Figure 1B). To be consistent, we analyzed the first motif of the first approach for each male.

In order to analyze the trajectory and velocity of a male courtship motif, we traced the locations of the male snout relative to the female snout, because the tip of the snout is a reliable landmark that can be easily traced and is a good proxy for the male red throat and the female eyes (Figure 2A). ImageJ software (http://rsb.info.nih.gov/ij/) was used for digitization. The position of the male snout at the starting point of the approach was defined as the origin for determination of the coordinates (Figure 2A). The female was confined in a compartment and did not move substantially during a single motif of a courtship dance, so we used the position of the female snout at the starting point of the approach as the female position throughout the courtship dance. The coordinates of the male snout position were rotated around the origin to align the female snout on the horizontal $x$-axis. If necessary, images were flipped along the $x$-axis to transform the outside step of the male into a positive value. To calculate kinematic variables, we used the MSE quintic spline method (Woltring, 1985; Walker, 1998, 2004). Briefly, the coordinate data were smoothed with a quintic spline function using the true predicted mean-square error to estimate the smoothing parameter using QuickSAND software (Walker, 1997, 1998). We measured the distance traveled toward the female and toward the side during a single motif $\left(\mathrm{x}_{2}\right.$ and $\mathrm{y}_{2}$, respectively, in Figure 2A), the maximum amplitude of the outside step ( $\mathrm{y}_{1}$ in Figure 2A), and average and maximum velocities along the $x$ - and $y$-axes. Velocities along the $y$-axis were analyzed separately for the outside step (from the origin to $\mathrm{x}_{1}, \mathrm{y}_{1}$ in Figure $2 \mathrm{~A}$ ) and for the inside step (from $\mathrm{x}_{1}, \mathrm{y}_{1}$ to $\mathrm{x}_{2}$, $\mathrm{y}_{2}$ in Figure 2A).

We also examined whether the size of the male or the male position relative to the female influenced the kinematics of the male dance. We measured the standard length of each male after the behavioural experiments and also calculated the distance between the male snout and the female snout at the start of the courtship dance as described above. Then, we tested the correlation between these variables and the kinematic variables using the Spearman rank correlation.

\section{Analysis of mouth opening and throat extension}

For analysis of mouth opening and throat extension, we used a digital camcorder to record the male approach from the female side at $30 \mathrm{fps}$. We used 
the experimental set-up described above except that we used a glass tank (30 $\mathrm{cm}$ wide $\times 75 \mathrm{~cm}$ long $\times 20 \mathrm{~cm}$ deep) that was divided into a small female compartment $(30 \mathrm{~cm}$ wide $\times 15 \mathrm{~cm}$ long $\times 20 \mathrm{~cm}$ deep $)$ and a large male compartment $(30 \mathrm{~cm}$ wide $\times 60 \mathrm{~cm}$ long $\times 20 \mathrm{~cm}$ deep $)$ by a transparent partition.

Approaches of five PA and five JA males were observed from the female side. A gravid female of the conspecific form was shown to each male, and for each male we analyzed the videos of five zig-zag or five rolling approaches that started from the nest site and ended in front of the female. We counted the number of frames in which the male opened his mouth and extended his throat during a single approach and divided it by the total frame number of the approach to calculate the frequency of mouth opening and the frequency of throat extension, respectively. For each individual, we calculated the median of the frequency of the five approaches to avoid pseudoreplication (Martin \& Bateson, 1993).

\section{Analysis of gill cover erection}

For comparing the frequency of gill cover erection, we analyzed videos of the courtship approach recorded from the female side in a glass tank $(30 \mathrm{~cm}$ wide $\times 75 \mathrm{~cm}$ long $\times 20 \mathrm{~cm}$ deep). We analyzed 10 approaches from each fish ( $N=10$ for JA males; $N=9$ for PA males) and counted how many approaches contained the gill cover erection behaviour.

In order to investigate how widely the fish erected the gill cover during the courtship dance, we recorded the male approach dance from the dorsal side at $125 \mathrm{fps}$ with a high-speed camera (Hi-DcamII, NAC Image Technology). An experimenter concealed behind a curtain watched the male behaviour from a small hole located in the curtain. Once the male started to perform an approach dance, the experimenter switched the trigger of the high-speed video to record the dance. Because the high-speed camera can only capture $6.5 \mathrm{~s}$ of video at a time, each video could capture only a single motif of one approach dance. Because of the short length of video time, it was very difficult to precisely capture the courtship dance and we were, thus, unable to record a consistent number of videos from an equal number of individuals. We obtained between 1 and 4 videos for each of three PA and six JA males. For each event of gill cover erection, we used ImageJ software to measure the head width before and during gill cover erection (Figure 3D). For JA males, 
head widths were measured from the image of a fish while it was upright, rather than while it was rolling. By dividing the head width during the display by the head width before the display, we calculated how widely the males erected the gill cover. For each fish, the median was used for calculating the population mean $\pm \mathrm{SE}$.

Nest weight analysis

In the behavioural experiments described above, we used $10 \mathrm{~g}$ of palm fiber as nesting material for each of the experimental tanks. After the behavioural experiments, nests were collected from the experimental tanks. After washing the nests with distilled water to remove the attached sand, the nest was wiped with Kimwipes (Kimberly-Clark, Canada) and weighed to the nearest $0.1 \mathrm{~g}$. The correlation between the standard length and the nest weight was tested by Spearman rank correlation. Means $\pm \mathrm{SE}$ are reported.

\section{Statistical analysis}

We first tested the homogeneity of variances between forms by Levene's test. The variances in the duration of a dance motif and the average velocity to female (Table 1) were significantly larger in JA males than in PA males $\left(F_{1,18}=25.740, p<0.001\right.$ for duration; $F_{1,18}=4.498, p=0.048$ for average velocity to female). Therefore, the duration and the average velocity to female were transformed by reciprocal and log transformations, respectively (Sokal \& Rohlf, 2003). Since the variance of gill cover erection frequency was significantly larger in PA males than in JA males $\left(F_{1,17}=7.398\right.$, $p=0.015)$, the gill cover erection frequency data were arcsine transformed before analysis (Sokal \& Rohlf, 2003). For all other traits analyzed, significant differences in variances between forms were not found $(p>0.10)$. ANOVA was used for comparison between forms.

\section{Results}

Divergence in the kinematics of the male courtship dance

Although there is individual variation in behaviour within forms, we found several significant differences between the zig-zag approaches of PA males and the rolling approaches of JA males (Table 1). The JA males took over 
Table 1. Kinematic variables of the zig-zag and rolling approaches. Means \pm SE are shown. ANOVA was used for comparison between forms.

\begin{tabular}{|c|c|c|c|c|}
\hline Kinematic variable & Zig-zag $(N=10)$ & Rolling $(N=10)$ & $F_{1,18}$ & $p$ \\
\hline Distance traveled to female $(\mathrm{mm})$ & $120.1 \pm 50.7$ & $123.8 \pm 73.8$ & 0.016 & 0.899 \\
\hline Distance traveled to side $(\mathrm{mm})$ & $30.1 \pm 16.7$ & $32.8 \pm 22.1$ & 0.096 & 0.940 \\
\hline Maximum amplitude of sidestep (mm) & $32.2 \pm 16.8$ & $39.8 \pm 23.3$ & 40.000 & 0.760 \\
\hline Duration $(\mathrm{s}) *$ & $0.563 \pm 0.190$ & $1.433 \pm 0.668$ & 15.710 & 0.001 \\
\hline Average velocity to female $(\mathrm{mm} / \mathrm{s})^{*}$ & $205.8 \pm 76.4$ & $97.8 \pm 48.2$ & 14.292 & 0.001 \\
\hline Average velocity to outside $(\mathrm{mm} / \mathrm{s})^{* *}$ & $91.3 \pm 54.8$ & $40.0 \pm 25.1$ & 7.260 & 0.015 \\
\hline Average velocity to inside $(\mathrm{mm} / \mathrm{s})$ & $-17.0 \pm 10.9$ & $-21.0 \pm 17.6$ & 0.086 & 0.773 \\
\hline Maximum velocity to female $(\mathrm{mm} / \mathrm{s})$ & $347.1 \pm 99.0$ & $278.1 \pm 161.7$ & 1.323 & 0.265 \\
\hline Maximum velocity to outside $(\mathrm{mm} / \mathrm{s})^{* *}$ & $186.0 \pm 95.1$ & $102.1 \pm 63.2$ & 5.400 & 0.032 \\
\hline Maximum velocity to inside $(\mathrm{mm} / \mathrm{s})$ & $-32.9 \pm 21.0$ & $-55.8 \pm 38.8$ & 1.439 & 0.246 \\
\hline
\end{tabular}

* Significant even after sequential Bonferroni correction.

${ }^{* *} p<0.05$, but not significant after sequential Bonferroni correction.

two times longer to perform a single motif of the rolling dance than the PA males took to perform a single motif of the zig-zag dance (see duration in Table 1; Figure 1). Reflecting this difference, the velocity of the zig-zag dance of PA males was greater than the velocity of the rolling dance of JA males for most variables, except the velocity of the inside step (Table 1). In contrast, the distance that the male snout traveled to the female or to the side at the end of the approach ( $\mathrm{x}_{2}$ and $\mathrm{y}_{2}$ in Figure 2A, respectively) did not differ significantly between the zig-zag approach and the rolling approach (Table 1). In addition, the maximum amplitude of the sideways step during a single motif of the courtship dance ( $y_{1}$ in Figure 2A) did not differ significantly between the zig-zag approach and the rolling approach (Table 1), suggesting that the overall trajectories of the two types of dances are relatively similar.

We found a slightly significant correlation between standard length and the velocities of the inside step in males who performed a rolling approach (Spearman rank correlation; $z=-0.762, p=0.044, N=10$ for average velocity; $z=-2.142, p=0.032, N=10$ for maximum velocity), although these data are not significant after sequential Bonferroni correction. We did not find any significant correlation between the standard length of the male and other kinematic variables in either form (Spearman rank correlation, $p>0.05, N=10$ ), nor did we find any significant correlations between any of the kinematic variables and the male's starting position in either form (Spearman rank correlation, $p>0.05, N=10$ ). 
A

Zigzag approach
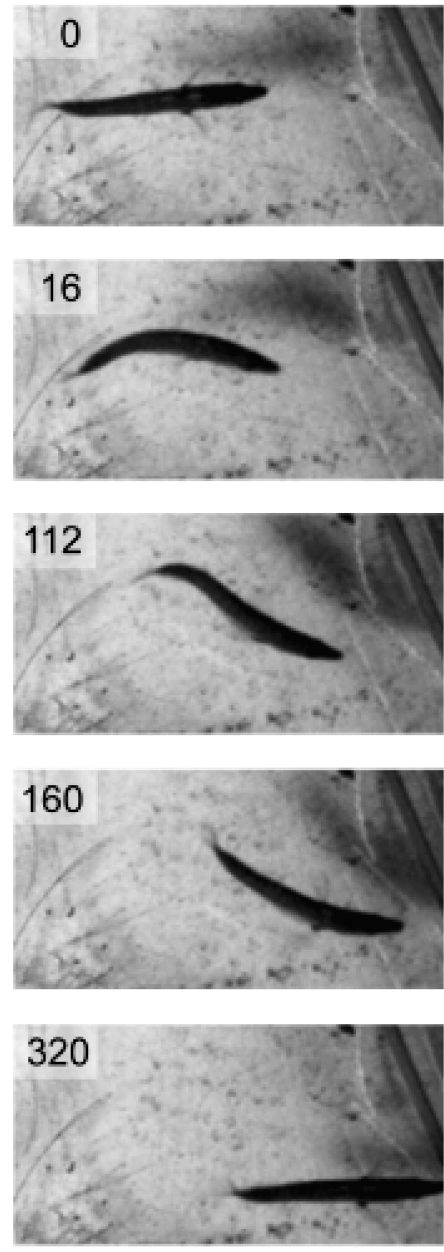

B

Rolling approach
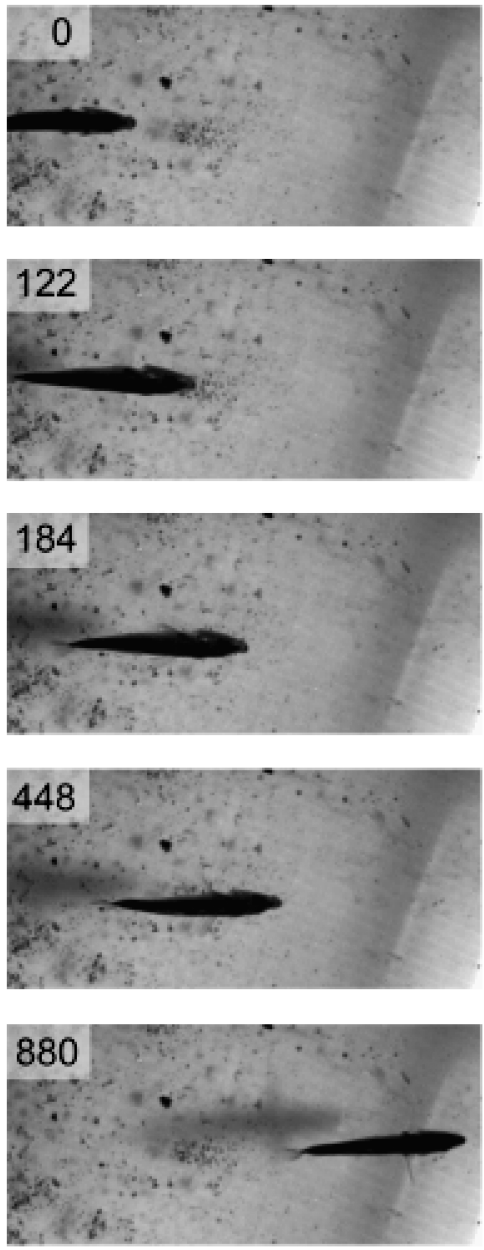

Figure 1. Body movements during a zig-zag approach of a Pacific Ocean male (A) and a rolling approach of a Japan Sea male (B). Male approaches were recorded from the dorsal side at $125 \mathrm{fps}$. Numbers in the figure indicate the time (ms) after the start of the approach.

\section{Divergence in mouth opening, throat extension and gill cover erection}

The JA males opened their mouths and extended their throats (Figure 3A) more frequently during the rolling dance than the PA males did during the zig-zag dance (Figure $3 \mathrm{C} ; F_{1,8}=16.65, p=0.004$ for mouth opening; $F_{1,8}=78.78, p<0.001$ for throat extension). Gill cover erection (Figure 
A

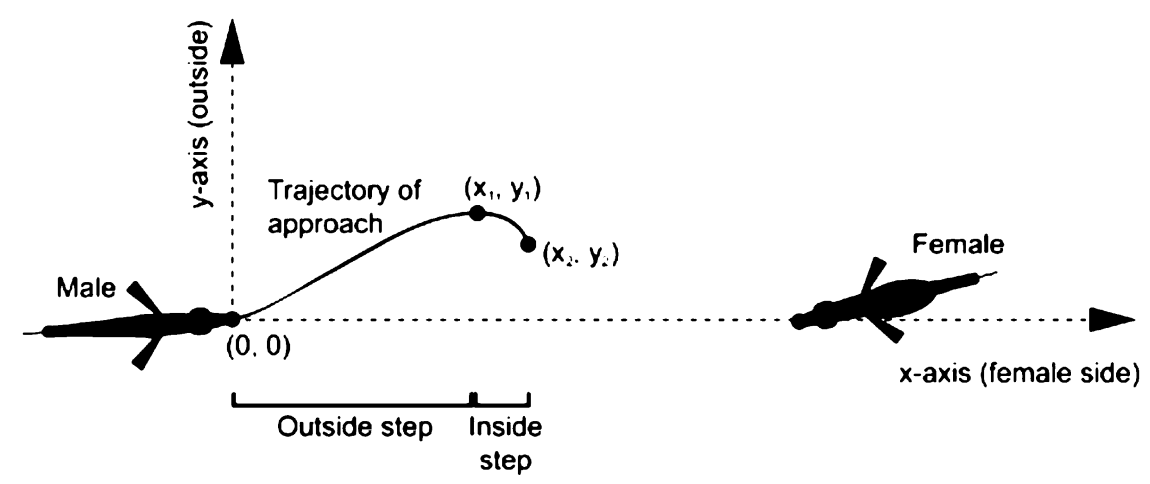

B

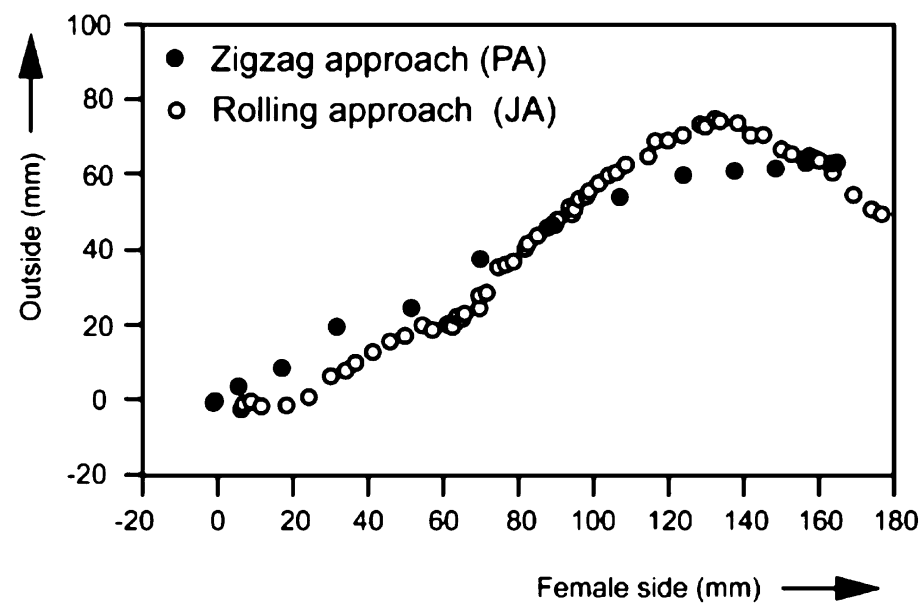

Figure 2. (A) Measurements of kinematic variables during the male courtship approach. The position of the male snout at the start of a single motif of the courtship dance was considered the origin $(0,0)$. The final position of the male snout at the end of a single motif is indicated as $\left(\mathrm{x}_{2}, \mathrm{y}_{2}\right)$. The male snout position when the male is furthest from the $x$-axis (outside) is indicated as $\left(\mathrm{x}_{1}, \mathrm{y}_{1}\right)$. (B) Representative trajectories of a single motif of PA male zig-zag approach (closed circles) and a single motif of a JA male rolling approach (open circles). Single dots represent the positions of the male snout recorded every $1 / 30 \mathrm{~s}$.

3B) was observed more frequently in the rolling approaches of JA males (93 $\pm 2.2 \%$ of the rolling approaches; $N=10 \mathrm{JA}$ males; 10 approaches for each male) than the zig-zag approaches of PA males $(37.8 \pm 13.4 \% ; N=9$ PA males; 10 approaches for each male; $\left.F_{1,17}=112.98, p<0.001\right)$. Even when PA males erected their gill covers, the head width is just $1.07 \pm 0.06$ times wider than before the display $(N=3)$. In contrast, when the JA males 
erect their gill covers, the head width became $1.30 \pm 0.09$ times wider than the head width before the display $(N=5)$.

\section{Divergence of nest weight}

We did not find any significant correlation between male standard length and nest weight within the populations ( $p=0.070, N=11$ for PA males; $p=0.194, N=16$ for JA males). However, we did find that PA males constructed significantly heavier nests $(4.5 \pm 0.5 \mathrm{~g})$ than JA males $(1.7 \pm 0.3$ $\left.\mathrm{g} ; F_{1,25}=27.659, p<0.001\right)$.

\section{Discussion}

The zig-zag dance of PA males is about two times faster than the rolling dance of JA males. The tempo of the zig-zag dance is important for the effective induction of a female response (Rowland, 1995). For example, in an Atlantic population, females responded to videos of the zig-zag dance that were played back at normal speed or videos that were played back 1.5-2 times faster than normal, but did not respond very well to videos that were played back at either half speed or at a much faster speed (Rowland, 1995). Thus, there may be an optimum speed at which the male dance attracts females, and this optimum speed may differ for females of the PA and JA forms. It is hypothesized that movement plays a more important role in dense habitats than in open habitats, because motion can effectively draw the receiver's attention in the presence of moving backgrounds of dense vegetation (McKenzie \& Keenleyside, 1970; Fleishman, 1992; Peters \& Evans, 2003). In a region where the two forms are breeding in sympatry, the JA males tend to breed in the more open habitat, while the PA males tend to breed in a more complex vegetated habitat (Kume et al., 2005). Additional studies on the breeding habitats of multiple sympatric populations of these two forms will be required to understand the relationship between breeding ecology and courtship divergence in the Japanese sympatric pair.

In many stickleback populations, males roll their bodies during both nestshowing behaviour and dorsal pricking behaviour (McLennan et al., 1988). Therefore, it is possible that the Japan Sea form has incorporated one or both of these behavioural components into their courtship dance. Although nestshowing behaviour did not appear to be different between the two forms (Kitano, unpubl. obs.), the Japan Sea forms consistently perform more vigorous 

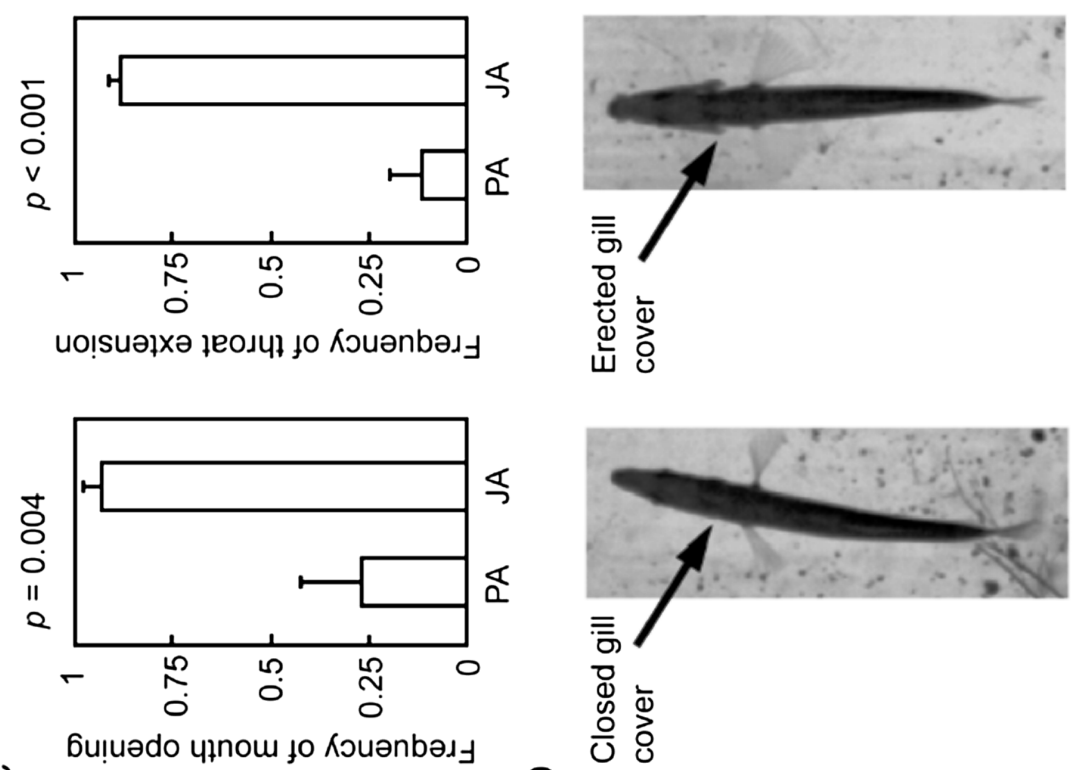

0

6u!̣ıədo ułnou to Кวuənbəג」
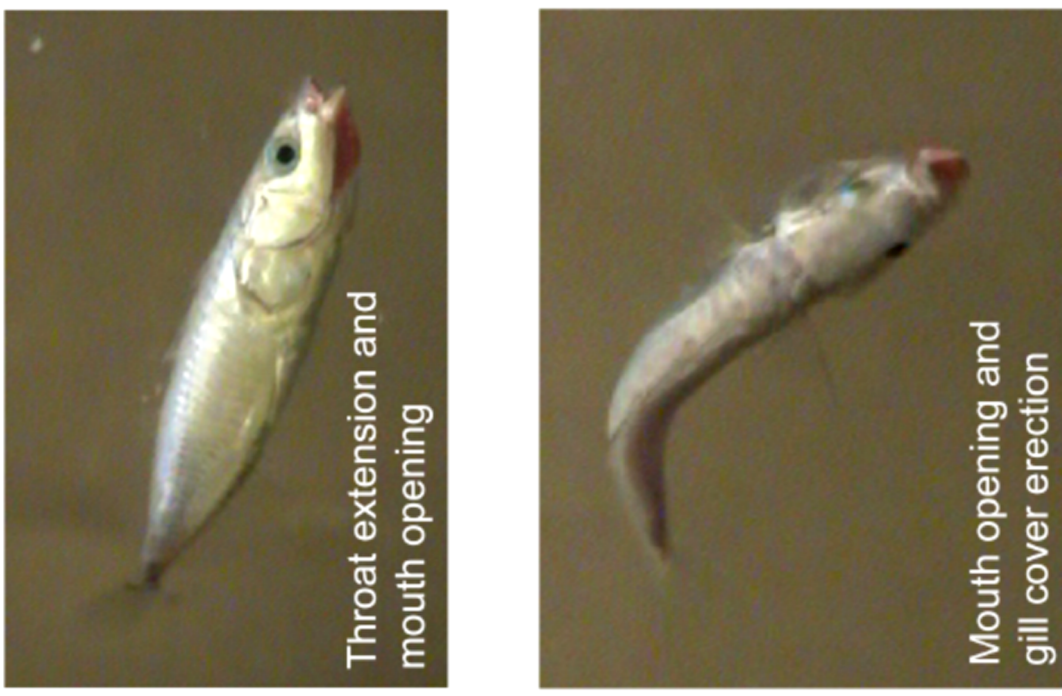

$\varangle$

$\infty$ 
dorsal pricking than the PA forms (Ishikawa \& Mori, 2000; Ishikawa et al., 2006; Kitano et al., 2007). Investigation of the genetic correlation between different behavioural components (e.g., Bell, 2005) may help to understand the evolutionary origin of the rolling dance.

Mouth opening, throat extension and gill cover erection were more frequently observed in the rolling dance of JA males than in the zig-zag dance of PA males. However, the functions of these behaviours during stickleback courtship remain elusive. Previously, a positive association between the zig-zag dance and mouth opening was reported from an Atlantic Ocean population of stickleback (Tinbergen, 1953; Symons, 1965). However, in the Japanese sympatric pair, the rolling JA males open their mouths more frequently than the zig-zagging PA males. Mouth opening has also been observed in allopatric Japan Sea populations (Ishikawa et al., 2006), suggesting that the associations between behavioural components differ across populations. Because the red throat coloration of male threespine stickleback is an important ornament for attracting females (Rowland, 1994; Rowe et al., 2004), throat extension and mouth opening in the JA males may help to enhance the presentation of red coloration, which is particularly intense inside the mouth and on the ventral side of the throat, but not very intense on the lateral side of the body in JA males (Kitano et al., unpubl. data; Figure 3). Expansion of conspicuous throat ornaments is widely seen in the animal kingdom (Darwin, 1874); specific examples include extension of a pigmented dewlap in anoline lizards (Williams \& Rand, 1977; Fleishman, 1992), inflation of a red throat pouch in the great frigatebird (Dearborn \& Ryan, 2002), and vocal sac inflation in frog (Rosenthal et al., 2004). Displays of the colorful interior of the mouth have also been observed in birds, such as the tooth-billed bowerbird (Frith \& Frith, 1993).

Gill cover erection is prevalent in male-male agonistic interactions in several teleost fish species, such as Siamese fighting fish (Robertson \& Sale, 1974; Polnau \& Ma, 2001), cichlids (Baerends \& Baerends, 1950) and river

Figure 3. (A) Throat extension and mouth opening in a JA male during the rolling dance. (B) Mouth opening and gill cover erection in a JA male during the rolling dance. (C) Comparison of the frequency of mouth opening and throat extension between PA and JA males. Means $\pm \mathrm{SE}$ are shown. $N=5$ for each population. (D) Dorsal view of gill cover erection during the rolling dance of a JA male. This figure is published in colour at http://www.ingenta.com 
bullhead (Morris, 1954), and is thought to help the fish look bigger in malemale combat. Although we have not observed gill cover erection during male-male agonistic interactions in the JA males (Kitano et al., unpubl. data), female threespine stickleback of several populations, including the JA population, have a preference for larger males (Moodie, 1982; Rowland, 1989a; Kitano et al., unpubl. data). Thus, it is possible that gill cover erection in JA males may help the males look bigger during courtship to compensate for their smaller body size, which might result from adaptation of the JA forms to different ecological resources than those of the PA forms (Kitano et al., 2007).

Our previous mate choice experiments revealed asymmetric sexual isolation: PA females strongly prefer PA males, while JA females show no preference for JA males over PA males (Kitano et al., 2007). These data suggest that the PA and JA females have different mating preferences. Because the sympatric PA and JA males have diverged in both the tempo and the motor patterns of their courtship displays, as well as in several other mating signals, including body size and nuptial color (Kitano et al., 2007), females could use any or all of these signals in making mate choice decisions. In addition, female sticklebacks can use the male nest as a signal in mate choice (Östlund-Nilsson, 2000, 2001; Barber et al., 2001; Östlund-Nilsson \& Holmlund, 2003), and we found that nest sizes were significantly different between the sympatric forms, with PA males building larger nests. Nest area and shape also differ between the Japanese sympatric forms (M. Kume, pers. commun.), suggesting that nest divergence might also contribute to reproductive isolation between the sympatric Japanese sticklebacks. Further mate choice experiments will allow us to dissect the roles of different male mating signals in female mate choice and sexual isolation between the Japanese sympatric pair.

Although variation in courtship behaviour has been observed between many stickleback populations (Wilz, 1973; McPhail \& Hay, 1983; Ridgway \& McPhail, 1984; Foster, 1994, 1995, 1999; Foster et al., 1996; Hay \& McPhail, 2000; Boughman et al., 2005), we know very little about the relative contributions of genetic and environmental factors to behavioural variation. A recent study has shown that there is a great deal of phenotypic plasticity in male courtship behaviours within a population, although there may also be a genetic component to differences between populations (Shaw et al., 
2007). Male sticklebacks can change their reproductive behaviour depending on the stage of breeding season (Symons, 1965; Kynard, 1978; Mori, 1993), female receptivity (Rowland, 2002), or female morphology (Rowland, 1982, 1989b). In this study, we have only investigated the first dance that male performed and, thus, did not examine temporal changes in behaviour throughout courtship. However, the PA and JA males perform divergent courtship behaviours in the laboratory throughout the breeding season of May-July (Ishikawa \& Mori, 2000; Ishikawa et al., 2006; Kitano et al., 2007; this study). Furthermore, most components of the divergent courtship behaviours that have been found in wild-caught fish also differ between laboratoryreared PA and JA forms (Kitano \& Peichel, unpubl. data), suggesting that there is a genetic component to courtship divergence in the Japanese stickleback sympatric pair. Together with the feasibility of making hybrids between these forms (Kitano et al., 2007) and the availability of genomic tools in stickleback (Peichel et al., 2001; Kingsley \& Peichel, 2007), it should be possible to use the Japanese sympatric pair as a system to study the genetic architecture of evolutionary changes in the kinematics and motor patterns of courtship behaviour.

\section{Acknowledgements}

We thank M. Kume for fish collection and discussion, J. Kitajima and M. Nishida for technical assistance, and all members of the Peichel Lab, especially A. Bruner, for fish care. We thank A. Greenwood and three anonymous reviewers for constructive comments that greatly improved the manuscript. J.K. was a Uehara Memorial Foundation Fellow and Instructor of Kyoto University. This research was supported in part by a Career Award in the Biomedical Sciences from the Burroughs Wellcome Fund to C.L.P. and by Grant-in-Aid for Scientific Research from the Ministry of Education, Culture, Sports, Science and Technology of Japan, and Japan Fund for Global Environment from Environment Restoration and Conservation of Japan to S.M.

\section{References}

Barber, I., Nairn, D. \& Huntingford, F.A. (2001). Nests as ornaments: revealing construction by male sticklebacks. — Behav. Ecol. 12: 390-396.

Baerends, G.P. \& Baerends-van Roon, J.M. (1950). An introduction to the study of the ethology of cichlid fishes. - Brill, Leiden.

Bell, A.M. (2005). Behavioural differences between individuals and two populations of stickleback (Gasterosteus aculeatus). — J. Evol. Biol. 18: 464-473. 
Bell, M.A. \& Foster, S.A. (1994). The evolutionary biology of the threespine stickleback. Oxford University Press, Oxford.

Boughman, J.W., Rundle, H.D. \& Schluter, D. (2005). Parallel evolution of sexual isolation in sticklebacks. - Evolution 59: 361-373.

Brown, W.M., Cronk, L., Grochow, K., Jacobson, A., Liu, C.K., Popovic, Z. \& Trivers, R. (2005). Dance reveals symmetry especially in young men. — Nature 438: 1148-1150.

Cooper, B.G. \& Goller, F. (2004). Multimodal signals: enhancement and constraint of song motor patterns by visual display. - Science 303: 544-546.

Darwin, C. (1874). The descent of man; and selection in relation to sex. - Humbolt, New York, NY.

Dearborn, D.C. \& Ryan, M.J. (2002). A test of the Darwin-Fisher theory for the evolution of male secondary sexual traits in monogamous birds. - J. Evol. Biol. 15: 307-313.

Fleishman, L.J. (1992). The influence of the sensory system and the environments on motion patterns in the visual displays of anoline lizards and other vertebrates. - Am. Nat. 139: S36-61.

Foster, S.A. (1994). Evolution of the reproductive behaviour of threespine stickleback. - In: The evolutionary biology of the threespine stickleback (Bell, M.A. \& Foster, S.A., eds). Oxford University Press, Oxford, p. 381-398.

Foster, S.A. (1995). Understanding the evolution of behaviour in threespine stickleback: the value of geographic variation. - Behaviour 132: 1107-1129.

Foster, S.A. (1999). The geography of behaviour: an evolutionary perspective. — Trends Ecol. Evol. 14: 190-195.

Foster, S.A., Cresko, W.A., Johnson, K.P., Tlusty, M.U. \& Willmott, H.E. (1996). Patterns of homoplasy in behavioural evolution. - In: Homoplasy and the evolutionary process (Saunders, M.D. \& Hufford, L., eds). Academic Press, New York, NY, p. 245-269.

von Frisch, K. (1967). The dance language and orientation of bees. - Belknap Press, Cambridge.

Frith, C.B. \& Frith, D.W. (1993). Courtship display of the tooth-billed bowerbird and its behavioural and systematic significance. - Emu 93: 129-136.

Haglund, T.R., Buth, D.G. \& Lawson, R. (1992). Allozyme variation and phylogenetic relationships of Asian, North American, and European populations of the threespine stickleback, Gasterosteus aculeatus. - Copeia: 432-443.

Hailman, J.P. (1977). Optical signals: animal communication and light. — Indiana University Press, Bloomington, IN.

Hay, D.E. \& McPhail, J.D. (2000). Courtship behaviour of male threespine sticklebacks (Gasterosteus aculeatus) from old and new hybrid zones. - Behaviour 137: 1047-1063.

Higuchi, M. \& Goto, A. (1996). Genetic evidence supporting the existence of two distinct species in the genus Gasterosteus around Japan. - Environ. Biol. Fishes 47: 1-16.

van Iersel, J.J.A. (1953). An analysis of the parental behaviour of the male three-spined stickleback (Gasterosteus aculeatus L.). - Behaviour Suppl. 3: 1-159.

Ikeda, K. (1933). The distribution and the morphological variations of sticklebacks in Japan. —Zool. Mag. Tokyo 45: 141-173.

Ishikawa, M. \& Mori, S. (2000). Mating success and male courtship behaviours in three populations of threespine stickleback. - Behaviour 137: 1065-1080.

Ishikawa, M., Mori, S. \& Nagata, Y. (2006). Intraspecific differences in patterns of courtship behaviours between the Pacific Ocean and Japan Sea forms of the three-spined stickleback Gasterosteus aculeatus. — J. Fish. Biol. 69: 938-944. 
Jamieson, I.G. \& Colgan, P.W. (1989). Eggs in the nests of males and their effect on mate choice in the three-spined stickleback. - Anim. Behav. 38: 859-865.

Kingsley, D.M. \& Peichel, C.L. (2007). The molecular genetics of evolutionary change in sticklebacks. - In: Biology of the three-spined stickleback (Östlund-Nilsson, S., Mayer, I. \& Huntingford, F.A., eds). CRC Press, Boca Raton, FL, p. 41-81.

Kitano, J., Mori, S. \& Peichel, C.L. (2007). Phenotypic divergence and reproductive isolation between sympatric forms of Japanese threespine sticklebacks. — Biol. J. Linn. Soc. 91: 671-685.

Kume, M., Kitamura, T., Takahashi, H. \& Goto, A. (2005). Distinct spawning migration patterns in sympatric Japan Sea and Pacific Ocean forms of threespine stickleback Gasterosteus aculeatus. — Ichthyol. Res. 52: 189-193.

Künzler, R. \& Bakker, T.C.M. (2001). Female preferences for single and combined traits in computer animated stickleback males. - Behav. Ecol. 12: 681-685.

Kynard, B.E. (1978). Breeding behaviour of a lacustrine population of threespine sticklebacks (Gasterosteus aculeatus). - Behaviour 67: 178-207.

Lorenz, K. (1958). The evolution of behaviour. — Sci. Am. 199: 67-78.

Martin, P. \& Bateson, P. (1993). Measuring behaviour. - Cambridge University Press, Cambridge.

Mayr, E. (1942). Systematics and the origin of species. - Columbia University Press, New York, NY

McKenzie, J.A. \& Keenleyside, M.H.A. (1970). Reproductive behaviour of ninespine sticklebacks (Pungitius pungitius L.) in South Bay, Manitoulin Island, Ontario. - Can. J. Zool. 48: 55-61.

McKinnon, J.S. \& Rundle, H.D. (2002). Speciation in nature: the threespine stickleback model systems. - Trends Ecol. Evol. 117: 480-488.

McLennan, D.A., Brooks, D.R. \& McPhail, J.D. (1988). The benefits of communication between comparative ethology and phylogenetic systematics: a case study using gasterosteid fishes. - Can. J. Zool. 66: 2177-2190.

McPhail, J.D. \& Hay, D.E. (1983). Differences in male courtship in freshwater and anadromous sticklebacks (Gasterosteus aculeatus). — Can. J. Zool. 61: 292-297.

Milinski, M. \& Bakker, T.C.M. (1990). Female sticklebacks use male coloration in mate choice and hence avoid parasitized males. - Nature 344: 330-333.

Moodie, G.E.E. (1982). Why asymmetric mating preferences may not show the direction of evolution. - Evolution 36: 1096-1097.

Mori, S. (1993). The breeding system of the three-spined stickleback, Gasterosteus aculeatus (forma leiura) with reference to spatial and temporal patterns of nesting activity. Behaviour 126: 97-124.

Morris, D. (1954). The reproductive behaviour of the river bullhead (Cottus gobio L.), with special reference to the fanning activity. - Behaviour 7: 1-31.

Östlund-Nilsson, S. (2000). Are nest characters of importance when choosing a male in the fifteen-spined stickleback (Spinachia spinachia)? — Behav. Ecol. Sociobiol. 48: 229235.

Östlund-Nilsson, S. (2001). Fifteen-spined stickleback (Spinachia spinachia) females prefer males with more secretional threads in their nests: an honest-condition display by males. — Behav. Ecol. Sociobiol. 50: 263-269.

Östlund-Nilsson, S. \& Holmlund, M. (2003). The artistic three-spined stickleback (Gasterosteus aculeatus). - Behav. Ecol. Sociobiol. 53: 214-220. 
Partan, S. \& Marler, P. (1999). Communication goes multimodal. — Science 283: 1272-1273.

Peichel, C.L., Nereng, K.S., Ohgi, K.A., Cole, B.L.E., Colosimo, P.F., Buerkle, C.A., Schluter, D. \& Kingsley, D.M. (2001). The genetic architecture of divergence between threespine stickleback species. - Nature 414: 901-905.

Peters, R.A. \& Evans, C.S. (2003). Design of the Jacky dragon visual displays: signal and noise characteristics in a complex moving environment. - J. Comp. Physiol. A 189: 447-459.

Polnau, D.G. \& Ma, P.M. (2001). Simultaneous video analysis of the kinematics of opercular motion and electromyographic activity during agonistic display in Siamese fighting fish. — Brain Res. Brain Res. Protoc. 8: 228-235.

Ridgway, M.S. \& McPhail, J.D. (1984). Ecology and evolution of sympatric sticklebacks (Gasterosteus aculeatus): mate choice and reproductive isolation in Enos Lake species pair. — Can. J. Zool. 62: 1813-1818.

Robertson, C.M. \& Sale, P.F. (1974). Sexual discrimination in the Siamese fighting fish (Betta splendens regan). - Behaviour 54: 1-25.

Rosenthal, G.G., Rand, A.S. \& Ryan, M.J. (2004). The vocal sac as a visual cue in anuran communication: an experimental analysis using video playback. - Anim. Behav. 68: $55-58$.

Rowe, M.P., Baube, C.L., Loew, E.R. \& Phillips, J.B. (2004). Optimal mechanisms for finding and selecting mates: how threespine stickleback (Gasterosteus aculeatus) should encode male throat colors. - J. Comp. Physiol. A. 190: 241-256.

Rowland, W.J. (1982). Mate choice by male sticklebacks, Gasterosteus aculeatus. - Anim. Behav. 30: 1093-1098.

Rowland, W.J. (1989a). Mate choice and the supernormality effect in female sticklebacks (Gasterosteus aculeatus). — Behav. Ecol. Sociobiol. 24: 433-438.

Rowland, W.J. (1989b). The ethological basis of mate choice in male threespine sticklebacks, Gasterosteus aculeatus. - Anim. Behav. 38: 112-120.

Rowland, W.J. (1994). Proximate determinants of stickleback behaviour: an evolutionary perspective. - In: The evolutionary biology of the threespine stickleback (Bell, M.A. \& Foster, S.A., eds). Oxford University Press, Oxford, p. 297-344.

Rowland, W.J. (1995). Do female stickleback care about male courtship vigor? Manipulation of display tempo using video play back. - Behaviour 132: 951-961.

Rowland, W.J. (2002). Male preference for a subtle posture cue that signals spawning readiness in female sticklebacks. - Anim. Behav. 63: 743-748.

Sevenster, P. (1961). A causal analysis of a displacement activity (fanning in Gasterosteus aculeatus L.). - Behaviour Suppl. 9: 1-170.

Shaw, K.A., Scotti, M.L. \& Foster, S.A. (2007). Ancestral plasticity and the evolutionary diversification of courtship behaviour in threespine sticklebacks. - Anim. Behav. 73: 415-422.

Sokal, R.R. \& Rohlf, F.J. (2003). Biometry. - W.H. Freeman, New York, NY.

Symons, P.E.K. (1965). Analysis of spine-raising in the male three-spined stickleback. Behaviour 26: 1-74.

Tinbergen, N. (1951). The study of instinct. — Oxford University Press, Oxford.

Tinbergen, N. (1953). Social behaviour in animals, with special reference to vertebrates. Wiley, London.

Walker, J.A. (1997). QuickSAND. Quick Smoothing and Numerical Differentiation for the Power Macintosh. - Available online at http://jaw.fmnh.org/software/qs.html 
Walker, J.A. (1998). Estimating velocities and accelerations of animal locomotion: a simulation experiment comparing numerical differentiation algorithms. - J. Exp. Biol. 201: 981-995.

Walker, J.A. (2004). Dynamics of pectoral fin rowing in a fish with an extreme rowing stroke: the threespine stickleback (Gasterosteus aculeatus). — J. Exp. Biol. 207: 1925-1939.

Williams, E.E. \& Rand, S.A. (1977). Species recognition, dewlap function and faunal size. - Am. Zool. 17: 261-270.

Wilz, K.J. (1973). Quantitative differences in the courtship of two populations of three-spined sticklebacks, Gasterosteus aculeatus. - Z. Tierpsychol. 33: 141-146.

Woltring, H.J. (1985). On optimal smoothing and derivative estimation from noisy displacement data in biomechanics. - Hum. Mov. Sci. 4: 229-245.

Wootton, R.J. (1984). A functional biology of sticklebacks. — Croom Helm, London. 